\title{
Pronounced Cognitive Deficits Following an Intravenous L-Tryptophan Challenge in First-Degree Relatives of Bipolar Patients Compared to Healthy Controls
}

\author{
S Sobczak*,', A Honig', JAJ Schmitt' and WJ Riedel' \\ 'Brain and Behavior Institute, Department of Psychiatry and Neuropsychology, Universiteit Maastricht, Maastricht, The Netherlands
}

\begin{abstract}
Cognitive impairment has repeatedly been described in bipolar disorders (BD). Serotonin (5-hydroxytryptophan; 5-HT) is possibly involved in these cognitive processes, more particularly in executive functions, learning, memory, and attention. The aim of this study was to investigate serotonergic vulnerability and its relation to cognitive functioning in healthy first-degree relatives of BD patients. We investigated the effects of an intravenous (i.v.) tryptophan (Trp) challenge and placebo on cognitive performance in 30 healthy firstdegree relatives of bipolar patients $(\mathrm{FH})$ and 15 matched controls in a double-blind crossover design. A distinction was made between relatives of type I BD patients (FH I) and type II BD patients (FH II). Performances on planning, memory, attention, and psychomotor tasks were assessed $3 \mathrm{~h}$ after Trp infusion. After Trp, planning and attention were impaired in FH subjects but not in controls. Independent of Trp, FH subjects showed cognitive deficits on memory, focused and divided attention, and psychomotor performance. $\mathrm{FH}$ I subjects showed more pronounced cognitive impairments then $\mathrm{FH} \|$ and controls. In all groups, Trp impaired memory and psychomotor performance significantly. In conclusions, cognitive deficits in FH following Trp may reflect a central 5-HT vulnerability in frontal brain areas. Independent of Trp, cognitive deficits in $\mathrm{FH}$ provide evidence for a trait marker for BD.

Neuropsychopharmacology (2003) 28, 7 I I-719. doi: I 0. I038/s..npp. 1300055
\end{abstract}

Keywords: bipolar disorders; cognition; family history; serotonin; tryptophan challenge

\section{INTRODUCTION}

In bipolar disorders (BD), cognitive deficits have been reported repeatedly (Coffman et al, 1990; Savard et al, 1980; Wolfe et al, 1987; Krabbendam et al, 2000). Manic patients showed impairments on planning and reaction time (RT) (Murphy et al, 1999). During remission, cognitive deficits may persist (van Gorp et al, 1998; Ferrier et al, 1999; Rubinsztein et al, 2000; Scott et al, 2000); euthymic BD patients showed impairments on visuospatial recognition, verbal and nonverbal memory and learning, retrieval of information from semantic memory an increased RT on a planning task (Coffman et al, 1990; Ferrier et al, 1999; Rubinsztein et al, 2000). The fact that cognitive deficits persist during remission suggests that they constitute a trait marker in BD. Healthy first-degree relatives of BD patients (FH) provide a powerful design to investigate whether

\footnotetext{
*Correspondence: Dr A Honig, Institute of Brain and Behaviour, Department of Psychiatry, Maastricht University, University Hospital Maastricht (AZM), PO Box 5800, 6202 AZ Maastricht, The Netherlands, Tel: +31 43 3877537, Fax: +31 43 3875444, E-mail: adriaan.honig@spsy.azm.nl

Received 19 December 2001; revised 22 May 2002; accepted 29 August 2002

Online publication: 6 September 2002 at http://www.acnp.org/ citations/Npp090602375
}

cognitive deficits in $\mathrm{BD}$ reflect state or trait markers (Sobczak et al, 2000). Research on cognition in FH subjects who are free of psychopathology is new. In a previous study of our group, FH subjects showed impaired speed of information processing, on a planning task, and memory performance. Cognitive deficits seem to be more prevalent in relatives of patients with $\mathrm{BD}$ type I (FH I) compared to relatives of $\mathrm{BD}$ type II patients (FH II) (Sobczak et al, 2002c). There are no papers on cognition in FH subjects.

Serotonin (5-hydroxytryptophan; 5-HT) has been implicated in psychopathology of $\mathrm{BD}$ and has also been associated with cognitive performance, particularly learning and memory (Young et al, 1994; Riedel et al, 1999; Schmitt et al, 2000). Changes in cognitive performance following selective 5-HT modulations are important biological markers for brain 5-HT responsivity (Riedel et al, 2002). Serotonergic modulations can be achieved by either stimulation of the 5-HT system via 5-HT precursors, releasing agents, reuptake inhibitors and receptor agonists, or depletion of tryptophan, acute tryptophan depletion (ATD). ATD results in a transient decrease of central 5-HT. Acute 5-HT challenges showed impaired memory performance after 5- $\mathrm{HT}_{1 \mathrm{~A}}$ challenge with ipsapirone (Riedel et al, 2002) and impaired psychomotor performance after $5-\mathrm{HT}_{2 \mathrm{C}}$ challenge with m-CPP (Riedel et al, 2002) and i.v. Trp loading (Winokur et al, 1986). The relation between 5-HT 
functioning, biological vulnerability to $\mathrm{BD}$, and cognition can be investigated using 5 - $\mathrm{HT}$ challenge paradigms in $\mathrm{FH}$ subjects. Such a relation has been reported by a study of our group in which ATD impaired planning performance selectively in FH subjects. This suggests serotonergic vulnerability affecting frontal lobe areas (Sobczak et al, 2002c).

Intravenous L-Tryptophan (Trp) loading is a useful 5-HT challenge paradigm that can be applied to investigate cognitive effects following an overall stimulation of the brain 5-HT system.

The present study was designed to investigate 5 - $\mathrm{HT}$ related cognitive functioning following Trp challenge in $\mathrm{FH}$ subjects and healthy matched controls. To our knowledge, this is the first study on 5-HT challenge and cognition in $\mathrm{FH}$ subjects. The hypotheses were: Trp will induce more pronounced cognitive changes in FH subjects; FH subjects will show impaired planning and memory independent of Trp (implying a trait marker in BD); detrimental effects of Trp will be more pronounced in FH I; based on previous findings, Trp will improve frontal lobe mediated planning and attention whereas it will decrease memory and psychomotor performance independent of $\mathrm{FH}$.

\section{METHODS}

\section{Subjects}

Subjects were family members and healthy matched controls. Family members were recruited via BD patients treated at the Department of Psychiatry, University Hospital Maastricht, via the consumer organization for manicdepressive patients and their families, and via advertisements in local newspapers. Healthy control subjects were also recruited via a newspaper advertisement and were free from any psychiatric family history.

FH subjects had at least one first-degree relative with a type I BD or type II $\mathrm{BD}$ diagnosis. All subjects were interviewed with an abbreviated version of the Family History Research Diagnostic Criteria (FHRDC) to assess FH (Endicott $e t a l, 1975$ ). Individual diagnoses (type I or type II $\mathrm{BD}$, according to DSM IV) of the patients were verified via the patients' own psychiatrist.

A standardized psychiatric examination (Mini International Neuropsychiatric Interview; MINI) (Sheehan et al, 1994) was taken of all participants to examine the present psychiatric state according to DSM IV criteria. The Hamilton Depression Rating Scale (HDRS) (Hamilton, 1967), the Young Mania Rating Scale (YMRS) (Young et $a l, 1978$ ), and the SCL-90 (Arrindell and Ettema, 1986) were used to verify the absence of depressive, manic, and general psychiatric symptomatology.

Physical health was assessed by means of a health questionnaire, a standard physical examination by a physician, and urine screening. The urine test (Combur ${ }^{\circledR}$ ) included assessment of leukocytes, nitrite, $\mathrm{pH}$, protein, glucose, ketones, urobilinogen, bilirubin, and erythrocytes. A Quick View, one-step pregnancy test (Quidel ${ }^{\circledR}$ ) was carried out in female subjects to check for unsuspected pregnancy.

Exclusion criteria were current or past use of psychoactive medication (antidepressants, neuroleptics, and/or
Table I Demographic Characteristics. Mean \pm SE; ${ }^{*} p<0.05$

\begin{tabular}{lcc}
\hline Measure & FH & Controls \\
\hline FH I & $n=22$ & \\
FH II & $n=8$ & \\
Women & $n=20$ & $n=11$ \\
Men & $n=10$ & $n=4$ \\
Family members & & \\
$\quad$ Bipolar disorder & 1.3 & 0.0 \\
Age & $41 \pm 2.9$ & \\
IQ & $117 \pm 2.8$ & $40 \pm 3.7$ \\
& & $118 \pm 2.6$ \\
BMI & $25.3 \pm 0.6$ & $25.0 \pm 0.7$ \\
SCL-90 & $102.2 \pm 1.8$ & $98.7 \pm 1.8$ \\
YMRS & $0.7 \pm 0.2^{*}$ & $0.3 \pm 0.2$ \\
HDRS & $1.3 \pm 0.3 *$ & $0.3 \pm 0.2$ \\
\hline
\end{tabular}

anxiolytics) and lifetime psychiatric disorder including alcohol or drug abuse (all as indicated by the MINI), current active physical illness, lactation, and pregnancy.

Of the 47 subjects who participated, two did not complete the experiment for reasons unrelated to the study. The included subjects who completed the experiment were 30 FH (10 men and 20 women) and 15 controls (four men, 11 women). Table 1 shows the demographic characteristics of all subjects who completed the experiment. Relatives were children $(n=19)$, parents $(n=9)$, and siblings $(n=2)$. In all, 22 were FH I and eight were FH II subjects. The FH and control group did not differ significantly with respect to age, body mass index (BMI), intelligence quotient (IQ), and SCL-90 total score, but FH subjects scored significantly higher on baseline (HDRS) $[\mathrm{F}(1,43)=4.30, p<0.05]$ and YMRS $[\mathrm{F}(1,43)=4.71, p<0.05]$.

Of the female subjects, 21 were premenopausal and 10 were postmenopausal. A total of 13 women used oral contraceptives.

Each control subject was matched with two FH subjects with respect to sex, age, BMI, and IQ. Intelligence (IQ) was estimated using Groninger Intelligence Test (GIT) subtasks (Vocabulary, Mental Rotation, Mental Arithmetic, and Word Analogies) (Luteijn, 1966).

The Medical Ethics Committee of the University Hospital of Maastricht approved of the study. All participants signed informed consent.

\section{Experimental Design and Treatment}

The study was conducted according to a mixed between/ within groups $(3 * 2)$ design. The between-groups factor was FH with three levels: controls, FH I, and FH II. Treatment, the within-subjectsfactor, consisted of two levels: placebo and Trp loading. Trp and placebo were administered intravenous. The order of treatment was randomized. Administration was acccording to a double-blind, orderbalanced crossover design. The two test days were spaced 35 days apart.

i.v. Trp loading. Trp infusions were prepared by dissolving $7.0 \mathrm{~g}$ Trp in $1000 \mathrm{cc}$ water. Saline solution $(\mathrm{NaCl})$ was added to ensure an isotonic solution $(\mathrm{pH}=7.4)$. Each Trp solution 
was sterilized by passage through a $0.22-\mathrm{mm}$ polymer (Millipore) filter and tested for pyrogenicity and sterility. Saline solution $(1000 \mathrm{cc})$ was given on a separate day as a placebo mixture. The $1000 \mathrm{cc}$ solution was administered within $60 \mathrm{~min}$. The appearances of solutions were identical.

\section{Procedure}

To eliminate response bias due to premenstrual symptoms, all premenopausal women were tested in the follicular phase of the menstrual cycle (Menkes et al, 1994; Rasgon et al, 2000).

On each test day, the subjects arrived at 9.00 am after an overnight fast. Immediately after arrival the i.v. cannula was inserted in a forearm vein. At 10.00 am $\left(t_{0}\right)$, the saline solution, with or without Trp, was administered.

During the experiment, the subjects remained in the testing room, where they were allowed to do nonstrenuous activities. Subjects were allowed to drink decaffeinated coffee, herbal tea or water, and to eat protein-poor fruits like apples and oranges.

Blood samples for assessment of plasma Trp were taken at $t_{-30}, t_{60}, t_{75}, t_{90}$, and $t_{105}$ (all time points $t_{X}$ refer to $(-) X$ min (before)/after $t_{0}$ ). Cognitive assessment was completed at $t_{180}$.

\section{Cognitive Assessments}

The cognitive test battery took approximately $60 \mathrm{~min}$ to complete and consisted of tasks measuring planning, attention, psychomotor performance, and memory.

\section{Planning}

Computerized Tower of London (compu-TOL): Planning capacity was assessed by a modified version of the onetouch Tower of London (TOL) task (Owen et al, 1995; Sobczak et al, in press; Shallice, 1982). On a computer screen, two arrays of differently colored balls (red, yellow, and blue) on sticks were presented. The subject were requested to indicate the minimal number of steps necessary to rearrange the balls on the lower configuration to match the arrangement presented on the top half of the screen. The subjects had counted the number of moves and then respond by pressing the appropriate response button (2-5 steps) as quickly as possible. The complexity of the task is dependent on the minimal number of steps in which the rearrangement can be achieved: $2,3,4$, and 5 steps. Performance was indicated by median RT as a function of the number of steps. The number of correct responses was checked for possible confounding of the $\mathrm{RT}$ results.

\section{Secondary Outcome Variables}

\section{Attention}

Go/NoGo Task (GONT): The GONT measures response readiness. Every second, one digit (0-9) was shown on a computer screen for $500 \mathrm{~ms}$. The subject was asked to push a button as soon as he/she saw the digit except when he/she saw a 'target-digit'. The number of correct responses and RT to the digits (distracters) were assessed. This task was aimed at measuring attention failures and was adopted after a version described by Robertson et al (1997).

Stroop Color Word Test (SCWT): The SCWT has often been used to test focused attention and response inhibition (Stroop, 1935). The test consisted of three reading cards (color names, color patches, color names printed in incongruously colored ink) displaying each 100 stimuli. The outcome variable was interference which denotes the percentage extra time needed to complete the third card relative to the average of the first and second cards: (time card III/[(time card I+time card II) $/ 2$ ) $]$ ) $* 100 \%$ (Houx and Jolles, 1993).

Left/Right Choice Reaction Time (CRT): This is a parametric version of the well-known color-word response conflict task (Stroop, 1935). The words Left and Right are displayed either at the left or the right side of a computer screen. Response instructions are to respond quickly (by pressing a corresponding button) to the location of the word irrespective of its meaning. The output parameters are the RT and accuracy of responding as a function of task difficulty.

Dichotic Listening Task (DLT): The DLT measures both focused and divided attention for auditory stimuli (Kimura and D'Amico, 1989). Subjects received different auditory stimuli simultaneously through a headphone on each side. The test consisted of three subtasks, in which the subjects were instructed to focus to either the numbers presented in the left/right ear (focused attention) or both ears (divided attention) (Schmitt et al, 2000). Subjects were instructed to remember and identify the numbers on a computer screen. Performance on each subtask was calculated by the $A^{\prime}$ sensitivity measure (see VVLT).

\section{Psychomotor performance}

Motor Choice Reaction Time (MCRT): The MCRT measures sensorimotor speed (Houx and Jolles, 1993). The subjects held one button and were asked to press one of five other buttons located at equal distance from the hold button when lit. The subjects responded either to a single button (simple RT), to one of three buttons that lit up (three-choice RT), or to the right of the lit button (incompatible three-choice RT) as quickly as possible. Dependent variables were movement time (which indicates psychomotor RT) and initiation time (as a measure of information processing) as a function of task complexity.

\section{Memory}

The Visual Verbal Learning Test (VVLT): The VVLT measures short-term memory (STM) and long-term memory (LTM) performance (Schmitt et al, 2000; Lezak, 1995). The test consisted of a list of 30 monosyllabic words, which were presented in three trials on a computer screen. Each trial ended with a free verbal recall of the words (immediate recall: STM). The subject was requested to recall as many 
words as possible without prior presentation $30 \mathrm{~min}$ after the third trial (delayed recall: LTM). A yes/no recognition test, consisting of 15 formerly learned words and 15 new but comparable words (distracters), was given after the delayed recall test (recognition). The RTs were recorded. Performance on the recognition task (LTM) was measured as $A^{\prime}=1-1 / 4(\mathrm{fr} / \mathrm{cr}+(1-\mathrm{cr}) /(1-\mathrm{fr}))$, where $\mathrm{cr}$ is the proportion of correctly recognized words and fr is the proportion of falsely recognized (Pollack and Norman, 1964). Dependent variables were total number of correct words on immediate recall and delayed recall, $A^{\prime}$ and the median RT of correctly recognized target words as a measure of speed of retrieval from LTM.

Verbal Fluency Test (Fluency): The fluency test measures strategy-driven retrieval of information from semantic memory. The subjects are asked to report as many fourletter words with the same initial letter within one minute. The dependent variable is the number of correct reported words (Schmitt et al, 2000).

\section{Mood, Hormones, and Physical Side Effects}

Mood was assessed using the abbreviated Bimodal Profile of Mood States (POMS) (McNair et al, 1971). The severity of side physical effects was determined by a specially designed questionnaire (17 four-point items) (Sobczak et al, $2002 \mathrm{a})$. Both were completed at $10.30 \mathrm{am}\left(t_{30}\right)$, at $t_{60}, t_{90}$, and at $t_{120}$. Blood samples (to assess cortisol and prolactin) were taken at $t_{60}, t_{75}, t_{90}$, and $t_{105}$. The effects of Trp on mood, prolactin, and cortisol have been described elsewhere (Sobczak et al, 2002c).

\section{Statistical Analysis}

Outcome variables were analyzed using the General Linear Model (GLM) for repeated measures. The within-subjects factor was treatment (two levels: Trp or placebo); the between-subjects factor was family history (three levels: controls, FH I, or FH II). Univariate contrasts between groups were used to test the primary hypothesis of difference between controls and FH subjects (controls vs $\mathrm{FH} \mathrm{I+II)} \mathrm{as} \mathrm{well} \mathrm{as} \mathrm{the} \mathrm{hypotheses} \mathrm{of} \mathrm{differences} \mathrm{between}$ controls and FH I and FH II relatives separately (controls $v s$ FH I and controls $v s$ FH II).

Mann-Whitney-U tests were used to test differences in side effects.

Relations between effects of Trp (determined as difference: Trp minus placebo) on cognitive measures and mood, peak prolactin and cortisol responses (determined as maximal response after Trp minus placebo) were evaluated by means of Pearson's product moment correlation.

Statistical analyses were performed with SPSS 9.0 for Windows.

\section{RESULTS}

\section{Plasma Trp Levels}

Plasma Trp concentrations $[\mathrm{F}(1,42)=41.2, p<0.01]$ and ratio Trp:LNAAs $[\mathrm{F}(1,42)=22.6, p<0.01]$ were significantly higher at baseline in the placebo condition. $\mathrm{FH}$ subjects showed lower baseline plasma $\operatorname{Trp}[\mathrm{F}(1,42)=6.4$, $p<0.05$ ] compared to controls. After correction for baseline differences, plasma $\operatorname{Trp}[\mathrm{F}(1,42)=978.7, p<0.001]$ and ratio Trp:LNAAs $[\mathrm{F}(1,42)=502.3, p<0.001]$ increased significantly after i.v. Trp loading. Relative to baseline, the mean peak of plasma Trp and ratio Trp : LNAAs to i.v. Trp loading were $1049.4 \mathrm{~mol} / \mathrm{l}$, respectively 2.3. Following placebo, there was no change in plasma Trp and ratio Trp : LNAAs.

There were no effects of treatment order and $\mathrm{FH}$ on increase in Trp values after challenging. The values of plasma Trp are represented in Table 2.

\section{Cognitive Assessments}

Table 3 shows mean ( \pm SE) of planning variables, separated for $\mathrm{FH}$ and control subjects.

\section{Planning}

compu-TOL: The three-way interaction of FH by number of steps by $\operatorname{Trp}$ on number of correct responses was significant $[\mathrm{F}(3,41)=3.01, p<0.05]$, but there were no differences between FH I and FH II subjects. There was also a main effect of $\operatorname{Trp}[F(1,42)=85.53, p<0.01]$ on median RT and a significant two-way interaction of number of steps by Trp on median $\mathrm{RT}[\mathrm{F}(3,40)=21.50, p<0.01]$; median RT was increased significantly after Trp on the 3 and 4 steps problems but not on the 2 and 5 steps problems.

There were no effects of treatment order.

Table 4 shows mean ( \pm SE) of other outcome variables, separated for $\mathrm{FH}$ and control subjects.

Table 2 Mean ( \pm SE) of Plasma Tryptophan (Trp) and Ratio Trp: LNAAs (LNAAs: Valine, Leucine, Isoleucine, Tyrosine, Phenylalanine) after Placebo and Trp Challenge

\begin{tabular}{|c|c|c|c|c|}
\hline & \multicolumn{2}{|c|}{ Trp } & \multicolumn{2}{|c|}{ Trps LNAAs } \\
\hline & FH & Controls & $\mathbf{F H}$ & Controls \\
\hline \multicolumn{5}{|c|}{ Baseline $\left(t_{-30}\right)$} \\
\hline $\begin{array}{l}\text { Placebo } \\
\text { Trp }\end{array}$ & $\begin{array}{l}65.7(2.6) \\
56.4(1.8)\end{array}$ & $\begin{array}{l}79.8(5.2) \\
61.0(3.0)\end{array}$ & $\begin{array}{l}0.14(0.0) \\
0.12(0.0)\end{array}$ & $\begin{array}{l}0.15(0.0) \\
0.11(0.0)\end{array}$ \\
\hline \multicolumn{5}{|l|}{$t_{60}$} \\
\hline $\begin{array}{l}\text { Placebo } \\
\text { Trp }\end{array}$ & $\begin{array}{c}49.6(2.4) \\
1086.4(56.6)\end{array}$ & $\begin{array}{c}60.3(3.4) \\
\text { I I } 07.5(83.0)\end{array}$ & $\begin{array}{l}0.11(0.0) \\
2.40(0.17)\end{array}$ & $\begin{array}{l}0.11(0.0) \\
2.27(0.14)\end{array}$ \\
\hline \multicolumn{5}{|l|}{$t_{75}$} \\
\hline $\begin{array}{l}\text { Placebo } \\
\text { Trp }\end{array}$ & $\begin{array}{c}50.0(1.8) \\
879.7(32.1)\end{array}$ & $\begin{array}{c}57.7(2.9) \\
862.9(29.0)\end{array}$ & $\begin{array}{l}0.11(0.0) \\
2.00(0.10)\end{array}$ & $\begin{array}{l}0.11(0.0) \\
1.92(0.09)\end{array}$ \\
\hline \multicolumn{5}{|l|}{$t_{90}$} \\
\hline $\begin{array}{l}\text { Placebo } \\
\text { Trp }\end{array}$ & $\begin{array}{cl}48.1 & (1.7) \\
828.7 & (25.3)\end{array}$ & $\begin{array}{c}55.1(2.4) \\
828.2(30.9)\end{array}$ & $\begin{array}{l}0.10(0.0) \\
1.94(0.09)\end{array}$ & $\begin{array}{l}0.1 \mid(0.0) \\
1.86(0.09)\end{array}$ \\
\hline \multicolumn{5}{|l|}{$t_{105}$} \\
\hline $\begin{array}{l}\text { Placebo } \\
\text { Trp }\end{array}$ & $\begin{array}{c}48.5(2.0) \\
797.2(24.2)\end{array}$ & $\begin{aligned} 55.1 & (2.3) \\
786.5 & (25.2)\end{aligned}$ & $\begin{array}{l}0.10(0.0) \\
1.88(0.09)\end{array}$ & $\begin{array}{l}0.11(0.0) \\
1.79(0.08)\end{array}$ \\
\hline
\end{tabular}


Table 3 Mean $( \pm$ SE) of the Primary Cognitive Outcome Measures (Planning). Results are Broken Down by Family History (Controls; C/FH I/FH II) and Treatment (Trp/Placebo; P). ${ }^{*} p<0.05,{ }^{\mathrm{ts}} p<0.1$

\begin{tabular}{|c|c|c|c|c|}
\hline Measure & Treatment & $C(n=15)$ & FH I $(n=22)$ & FH II $(n=8)$ \\
\hline \multicolumn{5}{|c|}{ Computerised Tower of London test (compu-TOL) } \\
\hline \multicolumn{5}{|c|}{ Correct responses (\#) } \\
\hline \multirow[t]{2}{*}{2 steps } & Trp & $9.2(0.2)$ & $8.9(0.3)$ & $8.6(0.6)$ \\
\hline & $P$ & $9.7(0.2)$ & $8.6(0.4)$ & $9.0(0.5)$ \\
\hline \multirow[t]{2}{*}{3 steps } & Trp & $9.0(0.2)$ & $9.2(0.1)$ & $9.0(0.4)$ \\
\hline & $P$ & $8.9(0.4)$ & $8.6(0.4)$ & $9.0(0.3)$ \\
\hline \multirow[t]{2}{*}{4 steps } & Trp & $7.2(0.4)$ & $7.4(0.4)$ & $7.9(0.4)$ \\
\hline & $P$ & $7.9(0.4)$ & $8.0(0.4)$ & $8.1(0.9)$ \\
\hline \multirow[t]{2}{*}{5 steps } & Trp & $8.2(0.2)$ & $7.0(0.4)$ & $7.0(0.7)$ \\
\hline & $P$ & $8.3(0.4)$ & $7.3(0.5)$ & $8.8(0.5)$ \\
\hline \multicolumn{5}{|c|}{ Median reaction time (msec) } \\
\hline \multirow[t]{2}{*}{2 steps } & Trp & $4880(262)$ & $5425(433)$ & $6035(76 I)$ \\
\hline & $P$ & $5721(693)$ & $5899(603)$ & $5899(875)$ \\
\hline \multirow[t]{2}{*}{3 steps } & Trp* & $7170(896)$ & $7774(772)$ & 7885 (928) \\
\hline & $P$ & $6802(656)$ & $7514(690)$ & $7166(822)$ \\
\hline \multirow[t]{2}{*}{4 steps } & Trp* & 9941 (808) & | $\mid 155(|20|)$ & $9798(1163)$ \\
\hline & $P$ & $8797(738)$ & | $547(||||)$ & $9554(1256)$ \\
\hline \multirow[t]{2}{*}{5 steps } & Trp & | 3623 (1904) & $17665(1266)$ & 17225 (2242) \\
\hline & $P$ & I 5463 (1970) & I8347 (I 899) & $|664|$ (3024) \\
\hline
\end{tabular}

\section{Attention}

GONT: There was a significant interaction of Trp and FH on number of correct response inhibitions; after Trp FH subjects showed less correct response inhibitions $[\mathrm{F}(1,43)=8.76, p<0.01]$ but controls did not. There were no effects on RT of correct responses nor did performance differ between treatment order or FH I and FH II subjects.

SCWT: The interference measure of the Stroop test did not show significant effects of FH, Trp, and treatment order.

CRT: On incompatible stimuli RT showed a significant interaction effect of Trp and FH (both FH I and FH) [F(1, $43)=3.98, p<0.05]$; RT was impaired after Trp in FH but not in controls, and on number of correct responses this interaction was trend significant; FH subjects showed less correct responses after Trp. Independent of Trp, FH subjects tended to be slower on incompatible stimuli.

There were no significant effects of Trp and $\mathrm{FH}$ on accuracy or RT of compatible responses and there were no effects of treatment order.

DLT: $\mathrm{FH}$ subjects showed impaired performance on focused attention subtasks 'right' $[\mathrm{F}(1,43)=7.24, p<0.05]$ and divided attention subtask 'both' $[\mathrm{F}(1,43)=9.53$, $p<0.01]$ independent of Trp.

There were no main effects of Trp or treatment order. There were no differences between FH I and FH II.

MCRT: Movement time was increased after $\operatorname{Trp}[\mathrm{F}(1$, $43)=4.42, p<0.05]$ in $\mathrm{FH}$ and controls. There was a main effect of $\mathrm{FH}$ on movement time $[\mathrm{F}(1,43)=5.09, p<0.05]$; prolonged movement time in $\mathrm{FH}$ was due to prolonged movement time in FH I subjects $[\mathrm{F}(2,42)=4.24, p<0.05]$.
There were no effects on initiation time and of treatment order.

\section{Memory}

VVLT: Trp significantly impaired performance on delayed recall $[\mathrm{F}(1,43)=7.76, p<0.01]$ and recognition $A^{\prime}$ $[\mathrm{F}(1,43)=4.15, p<0.05]$. Performance on the recognition task showed a significant interaction of Trp with treatment order $[\mathrm{F}(1,43)=5.12, p<0.05]$; subjects receiving $\operatorname{Trp}$ on the first test day showed an improvement in $A^{\prime}$ following placebo on the second test day, whereas subjects receiving placebo first were also better on the second test day. Following Trp, there was a trend towards impaired immediate recall performance $[\mathrm{F}(1,43)=3.84, p<0.1]$.

Independent of Trp, performance on recognition $A^{\prime}$ was impaired in FH subjects $[\mathrm{F}(1,43)=5.93, p<0.05]$, more specifically in FH I subjects $[\mathrm{F}(2,42)=4.21, p<0.05]$. There were no effects on median RT of the recognition task.

Fluency: There were no effects of Trp, $\mathrm{FH}$, or treatment order on the number of correct reported words.

\section{Mood, Hormones, and Physical Side Effects}

Trp significantly increased feelings of anger $[\mathrm{F}(1,42)=6.52$, $p<0.05]$, depression $[F(1,42)=187.92, p<0.001]$, fatigue $[\mathrm{F}(1,42)=22.17, \quad p<0.01]$, tension $[\mathrm{F}(1,42)=6.06$, $p<0.05]$, and decreased feelings of vigor $[\mathrm{F}(1,42)=12.12$, $p<0.01]$ on the POMS. Prolactin $[\mathrm{F}(1,41)=30.17, p<0.01]$ and cortisol $[\mathrm{F}(1,41)=10.86, p<0.01]$ increased significantly after Trp. Hormonal and mood responses to Trp did not differ at baseline and between FH groups and controls. In the Trp condition, significantly more side effects $[\mathrm{Z}=-3.95, \mathrm{df}=1, p<0.001]$ were reported compared to the placebo condition. Reported side effects after Trp were 
Table 4 Mean ( \pm SE) of the Secondary Cognitive Outcome Measures (Attention, Psychomotor Speed, and Memory). Results are Broken Down by Family History (Controls; C/ $\mathrm{FH} \mathrm{I/FH} \mathrm{II)} \mathrm{and} \mathrm{Treatment} \mathrm{(Trp/Placebo;} \mathrm{P).}{ }^{*} p<0.05,{ }^{\mathrm{ts}} \mathrm{p}<0 . \mathrm{I}$

\begin{tabular}{|c|c|c|c|c|}
\hline Measure & Treatment & $C(n=15)$ & FH I $(n=22)$ & FH II $(n=8)$ \\
\hline \multicolumn{5}{|l|}{ Go/NoGo Task } \\
\hline $\begin{array}{l}\text { RT (msec) } \\
\text { No. correct (\#) }\end{array}$ & $\begin{array}{l}\text { Trp } \\
P \\
\text { Trp } \\
P\end{array}$ & $\begin{array}{l}325(10) \\
331(11) \\
8.8(0.3) \\
8.2(0.3)\end{array}$ & $\begin{array}{l}35 \mid(\mid 3) \\
342(\mid 1) \\
8.1(0.3)^{*} \\
8.6(0.3)\end{array}$ & $\begin{array}{l}323(18) \\
307(14) \\
8.0(0.5)^{*} \\
8.3(0.5)\end{array}$ \\
\hline \multicolumn{5}{|l|}{ Stroop Color Word Test } \\
\hline Interference (\%) & $\begin{array}{l}\text { Trp } \\
\text { P }\end{array}$ & $\begin{array}{l}41(1) \\
43(1)\end{array}$ & $\begin{array}{l}41(1) \\
41(1)\end{array}$ & $\begin{array}{l}37(1) \\
38(2)\end{array}$ \\
\hline \multicolumn{5}{|c|}{ Left/Right Choice Reaction Time } \\
\hline $\begin{array}{l}\text { RT (msec) } \\
\text { Incompatible } \\
\text { Compatible }\end{array}$ & $\begin{array}{l}\text { Trp } \\
P \\
\text { Trp } \\
P\end{array}$ & $\begin{array}{l}700(18) \\
712(21) \\
690(17) \\
686(24)\end{array}$ & $\begin{array}{l}772(26)^{*} \\
732(22) \\
711(16) \\
688(15)\end{array}$ & $\begin{array}{l}683(27)^{*} \\
661(17) \\
664(27) \\
661(15)\end{array}$ \\
\hline \multicolumn{5}{|l|}{ No. correct (\#) } \\
\hline $\begin{array}{l}\text { Incompatible } \\
\text { Compatible }\end{array}$ & $\begin{array}{l}\text { Trp } \\
P \\
\text { Trp } \\
P\end{array}$ & $\begin{array}{l}\text { I5.5(0.2) } \\
\text { I5.3(0.2) } \\
\text { I5.8(0.1) } \\
\text { I5.9(0.1) }\end{array}$ & $\begin{array}{l}\text { I } 5 . \mid(0.2)^{\mathrm{ts}} \\
\text { I } 5.5(0.2) \\
\text { I } 5.4(0.2) \\
\text { I } 5.5(0.2)\end{array}$ & $\begin{array}{l}\text { I } 5.4(0.3)^{\text {ts }} \\
\text { I } 5.4(0.3) \\
\text { I } 5.5(0.3) \\
\text { I } 5.6(0.2)\end{array}$ \\
\hline \multicolumn{5}{|l|}{ Dichotic Listening Task } \\
\hline $\begin{array}{l}A^{\prime}(\%) \\
\text { Right } \\
\text { Both }\end{array}$ & $\begin{array}{l}\text { Trp } \\
P \\
\text { Trp } \\
P\end{array}$ & $\begin{array}{l}94(9) \\
93(1) \\
86(8) \\
86(8)\end{array}$ & $\begin{array}{l}89(2) \\
89(2)^{*} \\
83(8)^{*} \\
83(7)^{*}\end{array}$ & $\begin{array}{l}79(5) \\
89(3) * \\
81(2)^{*} \\
82(2)^{*}\end{array}$ \\
\hline \multicolumn{5}{|c|}{ Motor Choice Reaction Time } \\
\hline $\begin{array}{l}\text { RT (msec) } \\
\text { Simple } \\
\text { Choice } \\
\text { Incompatible }\end{array}$ & $\begin{array}{l}\text { Trp } \\
P \\
\text { Trp } \\
P \\
\text { Trp } \\
P\end{array}$ & $\begin{array}{l}114(6) \\
110(7) \\
125(6) \\
123(7) \\
132(9) \\
130(10)\end{array}$ & $\begin{array}{l}121(7) \\
127(7) \\
131(7) \\
133(6) \\
139(8) \\
137(8)\end{array}$ & $\begin{array}{l}111(6) \\
105(5) \\
116(7) \\
115(6) \\
125(11) \\
119(8)\end{array}$ \\
\hline Movement RT (msec) & $\begin{array}{l}\text { Trp** } \\
\text { P }\end{array}$ & $\begin{array}{l}1046(28) \\
1032(33)\end{array}$ & $\begin{array}{l}\text { I I } 85(40) \\
\text { | I } 66(37)^{*}\end{array}$ & $\begin{array}{l}1087(40) \\
1049(30)\end{array}$ \\
\hline \multicolumn{5}{|l|}{ Visual Verbal Learning Test } \\
\hline \multicolumn{5}{|l|}{ No. correct words (\#) } \\
\hline $\begin{array}{l}\text { Immediate rec. } \\
\text { Delayed rec. }\end{array}$ & $\begin{array}{l}\text { Trpts } \\
\text { P } \\
\text { Trp* } \\
P\end{array}$ & $\begin{array}{l}42.6(2.8) \\
42.1(3.2) \\
14.5(1.5) \\
15.1(1.6)\end{array}$ & $\begin{array}{l}33.8(2.6) \\
38.8(3.0) \\
10.5(1.3) \\
12.8(1.5)\end{array}$ & $\begin{array}{l}40.6(4.5) \\
41.0(5.0) \\
14.1(2.4) \\
16.1(2.0)\end{array}$ \\
\hline Recognition $A^{\prime}(\%)$ & $\begin{array}{l}\text { Trp* } \\
\text { P }\end{array}$ & $\begin{array}{l}53(9) \\
58(7)\end{array}$ & $\begin{array}{l}56(5) \\
60(4)^{*}\end{array}$ & $\begin{array}{l}49(8) \\
49(6)\end{array}$ \\
\hline Recognition RT (msec) & $\begin{array}{l}\text { Trp } \\
\text { P }\end{array}$ & $\begin{array}{l}647(19) \\
640(19)\end{array}$ & $\begin{array}{l}833(39) \\
852(42)\end{array}$ & $\begin{array}{l}729(39) \\
713(24)\end{array}$ \\
\hline \multicolumn{5}{|l|}{ Verbal Fluency Test } \\
\hline No. correct words (\#) & $\begin{array}{l}\text { Trp } \\
\text { P }\end{array}$ & $\begin{array}{l}12.9(1.4) \\
11.8(1.0)\end{array}$ & $\begin{array}{l}\text { I I.0 (0.8) } \\
\text { I } 0.7(1.0)\end{array}$ & $\begin{array}{l}12.1(1.2) \\
12.4(1.5)\end{array}$ \\
\hline
\end{tabular}


tiredness, nausea, drowsiness, dizziness, headache, dullness, feelings of weakness, loss of concentration, and diminished energy. Side effects did not differ between FH I, FH II, or control subjects.

\section{Correlations of Behavioral, Physiological, and Cognitive Effects}

Following Trp, decrease in vigor was positively correlated with decrease in delayed recall performance on the VVLT $[r=0.39, p<0.01]$. Detrimental effects of Trp on recognition $A^{\prime}$ showed a significant positive correlation with peak cortisol response following $\operatorname{Trp}[r=0.37, p<0.05]$.

There were no significant correlations between other POMS subscales, prolactin response, and effects of Trp on planning, attention and psychomotor performance. There were no significant correlations of total physical side effects and dependent variables on cognitive tasks.

\section{DISCUSSION}

This is the first study that investigated 5-HT vulnerability in $\mathrm{FH}$ subjects and cognitive functioning in $\mathrm{FH}$ following Trp challenge. These findings are in line with a previous study of our group on ATD in FH, highlighting an important relation between 5-HT, trait markers to $\mathrm{BD}$, and cognition.

In sum, impaired planning performance and attention after Trp challenge was found in FH subjects but not in controls. There was no significant interaction of FH and Trp on memory and movement RT. Independent of Trp loading, FH subjects showed cognitive deficits on memory, psychomotor performance, focused and divided attention. Cognitive deficits on memory and psychomotor performance were more pronounced in FH I than in FH II. There was a main effect of Trp on memory and psychomotor performance; surprisingly, Trp impaired delayed recall memory performance and recognition.

Impaired performance in $\mathrm{FH}$ on planning and attention following Trp suggest central 5-HT vulnerability in frontal brain areas in these subjects (Dagher et al, 1999; Murphy et al, 1999; Owen et al, 1990; Rubinsztein et al, 2001). The findings on planning are in agreement with data of a previous study of our group, which showed pronounced planning deficits in FH following ATD (Sobczak et al, 2002c). Thus both a decrease and increase in central Trp may impair planning performance in $\mathrm{FH}$. We speculate that in $\mathrm{FH}$ subjects the 5-HT system may be vulnerable to manipulations. Independent of the direction of 5-HT modulations, acute changes in central 5-HT may be regarded as a stressor and thereby disturb the equilibrium of 5-HT activity transiently resulting in cognitive impairments. This hypothesis is consistent with the kindling and stress sensitization theory of Post et al (Post and Weiss 1997), which includes adaptations in second messengers, genetic transcription, receptors, neurotransmitters, and neurons that may occur in response to stressors and remain present during remission of symptoms. In FH subjects, who have a biological vulnerability to $\mathrm{BD}$, this stress sensitization may ultimately result in $\mathrm{BD}$ psychopathology.

After ATD, attention may be improved (Rosse et al, 1992; Schmitt et al, 2000; Sobczak et al, 2002c). We found impaired attention after Trp in FH, which is in agreement with a linear negative association of 5-HT with (focused) attention.

Independent of Trp, FH subjects showed cognitive deficits on memory, movement time, and attention. Cognitive impairments have previously been described in FH and also in manic, depressed, and euthymic BD patients (Sobczak et al, 2002c; Rossi et al, 2000; Martinez-Aran et al, 2000; Ferrier et al, 1999; Murphy et al, 1999; Rubinsztein et al, 2000). The cognitive deficits in BD may be partially explained by abnormalities in functional brain structures and/or metabolism (Stoll et al, 2000; Manji et al, 2000; van Gorp et al, 1999; Coffman et al, 1990). As cognitive impairments are present in $\mathrm{FH}$ and persist during clinical remission in $\mathrm{BD}$ patients, they may be regarded as trait markers (Henry et al, 1973; van Gorp et al, 1998; Murphy et al, 1999; Coffman et al, 1990; Ferrier et al, 1999; Rubinsztein et al, 2000).

There was a tendency of FH I subjects to show more cognitive impairments compared to FH II and controls, which is in agreement with previous findings (Sobczak et al, 2002c). FH II subjects appear to be more vulnerable to ATDinduced mood changes (Sobczak et al, 2002a). This may suggest a biological distinction in FH I and FH II (Sobczak et al, 2002c). It is speculated that cognitive deficits in $\mathrm{BD}$ type I resemble those described in primary psychotic disorders, whereas BD type II patients show more characteristics of primary affective disorders (Dickerson et al, 2001; Krabbendam et al, 2000; Borkowska and Rybakowski, 2001).

The unexpected Trp-induced decrements in memory indicate impairments in consolidation affecting LTM performance. As there was a trend towards impaired immediate recall performance, the effects on LTM might probably be ascribed to impairments in STM. Deficits in STM have also been described following acute 5-HT challenges with ipsapirone (Riedel et al, 2002) and fenfluramine (Luciana et al, 1998) in healthy subjects. The detrimental effects of Trp on memory were comparative with those described following ATD (Sobczak et al, 2002c; Riedel et al, 1999; Schmitt et al, 2000; Rubinsztein et al, 2001). The fact that both an increase and decrease in Trp results in memory dysfunctions may suggest that there is an optimal 5-HT level for cognitive performance.

The Trp-induced impairment on movement time on MCRT is in agreement with results of Winokur et al (1986), who showed decreased motor performance on a symbolcopying test following i.v. Trp. Impaired RT was associated with sedation in the study of Winokur et al (1986) but not in our study.

Possible confounding factors that might have interfered with cognitive effects of Trp are physical side effects and changes in mood and cortisol release following Trp. Direct effects of 5-HT on vigilance and the conversion of Trp to melatonin may explain the sedative effects of Trp (Cooper $e t$ al, 1991; Schmitt et al, 2002). Correlation analyses showed sedation to be positively associated with impaired memory performance. There were no interfering effects of mood and physical side effects. There was a positive association of cortisol response following Trp and memory performance; a higher cortisol response was associated with lower Trpinduced impairments on recognition (see also Sobczak et al, 2002b). A possible memory-enhancing effect of acute 
elevations of cortisol has been described before (Buchanan and Lovallo, 2001; Adler and Jajcevic, 2001). Thus, effects of Trp on memory might possibly have been influenced independently by both sedation and cortisol.

In conclusion, this study showed Trp-induced planning and attention impairments in FH subjects. These cognitive deficits suggest 5-HT vulnerability to BD psychopathology affecting frontal brain functions. Cognitive deficits in $\mathrm{FH}$ on memory, psychomotor performance, and attention independent of Trp provide evidence for a trait marker for BD. Independent of $\mathrm{FH}$, the major findings of $\operatorname{Trp}$ on cognition were impaired memory and psychomotor performance. It is suggested that an acute change in central 5-HT following Trp may disturb an optimal 5-HT activity in frontal and temporal brain areas and hence cause cognitive deficits.

\section{ACKNOWLEDGEMENTS}

This research was funded by a grant from the Theodore \& Vada Stanley Foundation to Dr A Honig and Dr WJ Riedel and conducted within the Brain \& Behaviour Institute. The authors thank Professor TW Robbins and Dr BJ Sahakian for their collaborative efforts enabling the use of the onetouch Tower of London, and Suzanne Teunisse and Anita van Oers for their efforts in data collection.

\section{REFERENCES}

Adler G, Jajcevic A (2001). Post-dexamethasone cortisol level and memory performance in elderly depressed patients. Neurosci Lett 298: 142-144.

Arrindell WA, Ettema JHM (1986). SCL-90. Een multidimensionele psychopathologie indicator [SCL-90. A multidimensional indicator of psychopathology]. Lisse, Swets \& Zeitlinger.

Borkowska A, Rybakowski JK (2001). Neuropsychological frontal lobe tests indicate that bipolar depressed patients are more impaired than unipolar. Bipolar Disorders 3: 88-94.

Buchanan TW, Lovallo WR (2001). Enhanced memory for emotional material following stress-level cortisol treatment in humans. Psychoneuroendocrinology 26: 307-317.

Coffman JA, Bornstein RA, Olson SC, Schwarzkopf SB, Nasrallah HA (1990). Cognitive impairment and cerebral structure by MRI in bipolar disorder. Biol Psychiatry 27: 1188-1196.

Cooper J, Bloom FE, Roth RH (1991). The Biochemical Basis of Neuropharmacology, 6th edn. Oxford University press: New York.

Dagher A, Owen AM, Boecker H, Brooks DJ (1999). Mapping the network for planning: a correlational PET activation study with the Tower of London task. Brain 122(Pt. 10): 1973-1987.

Dickerson FB, Sommerville J, Origoni AE, Ringel NB, Parente F (2001). Outpatients with schizophrenia and bipolar I disorder: do they differ in their cognitive and social functioning? Psychiatry Res 102: 21-27.

Endicott J, Andreasen NC, Spitzer RL (1975). Family HistoryResearch Diagnostic Criteria. Biometrics Research, New York State Psychiatric Institute.

Ferrier IN, Stanton BR, Kelly TP, Scott J (1999). Neuropsychological function in euthymic patients with bipolar disorder. $\mathrm{Br} J$ Psychiatry 175: 246-251.

Hamilton M (1967). Development of a rating scale for primary depressive illness. Br J Soc Clin Psychol 6: 278-296.
Henry GM, Weingartner H, Murphy DL (1973). Influence of affective states and psychoactive drugs on verbal learning and memory. Am J Psychiatry 130: 966-970.

Houx PJ, Jolles J (1993). Age-related decline of psychomotor speed: effects of age, brain health, sex and education. Perceptual Motor Skills 76: 195-211.

Kimura D, D'Amico C (1989). Evidence for subgroups of adextrals based on speech lateralization and cognitive patterns. Neuropsychologia 27: 977-986.

Krabbendam L, Honig A, Wiersma J, Vuurman EF, Hofman PA, Derix MM et al (2000). Cognitive dysfunctions and white matter lesions in patients with bipolar disorder in remission. Acta Psychiatr Scand 101: 274-280.

Lezak MD (1995). Neuropsychological Assessment, 3rd edn. Oxford University Press: New York.

Luciana M, Collins PF, Depue RA (1998). Opposing roles for dopamine and serotonin in the modulation of human spatial working memory functions. Cereb Cortex 8: 218-226.

Luteijn, F (1966). A new abbreviated Groninger Intelligence Test. Ned Tijdschr Psychol 21: 675-682.

Manji HK, Moore GJ, Chen G (2000). Clinical and preclinical evidence for the neurotrophic effects of mood stabilizers: implications for the pathophysiology and treatment of manicdepressive illness. Biol Psychiatry 48: 740-754.

Martinez-Aran A, Vieta E, Colom F, Reinares M, Benabarre A, Gasto C, Salamero M (2000). Cognitive dysfunctions in bipolar disorder: evidence of neuropsychological disturbances. Psychother Psychosom 69: 2-18.

McNair DM, Lorr M, Droppleman LF (1971). Manual for the Profile of Mood States. Educational and Industrial Testing Service: San Diego.

Menkes DB, Coates DC, Fawcett JP (1994). Acute tryptophan depletion aggravates premenstrual syndrome. J Affect Disord 32: 37-44.

Murphy FC, Sahakian BJ, Rubinsztein JS, Michael A, Rogers RD, Robbins TW et al (1999). Emotional bias and inhibitory control processes in mania and depression. Psychol Med 29: $1307-1321$.

Owen AM, Downes JJ, Sahakian BJ, Polkey CE, Robbins TW (1990). Planning and spatial working memory following frontal lobe lesions in man. Neuropsychologia 28: 1021-1034.

Owen AM, Sahakian BJ, Hodges JR, Polkey CE, Summers BA, Robbins TW (1995). Dopamine-dependent fronto-striatal planning deficits in early Parkinson's Disease. Neuropsychology 9: 126-140.

Pollack I, Norman DA (1964). A non-parametric analysis of recognition experiments. Psyconomic Sci 1: 125-126.

Post RM, Weiss SRB (1997). Kindling and stress sensitization. In: Young LT, Joffe RT (eds). Bipolar disorder. Bipolar disorder. Bilogical Models and their Clinical Application, 1st edn. Marcel Dekker Inc.: New York. pp 93-126.

Rasgon N, McGuire M, Tanavoli S, Fairbanks L, Rapkin A (2000). Neuroendocrine response to an intravenous L-tryptophan challenge in women with premenstrual syndrome. Fertil Steril 73: $144-149$.

Riedel WJ, Klaassen T, Deutz NEP, van Someren A, van Praag HM (1999). Tryptophan depletion in normal volunteers produces selective impairment in memory consolidation. Psychopharmacology 141: 362-369.

Riedel WJ, Klaassen T, Griez E, Honig A, Menheere PPCA, van Praag HM (2002). Dissociable hormonal, cognitive and mood responses to neuroendocrine challenge: evidence for receptorspecific serotonergic dysregulation in depressed mood. Neuropsychopharmacology 26: 358-367.

Robertson IH, Manly T, Andrade J, Baddeley BT, Yiend J (1997). 'Oops!': performance correlates of everyday attentional failures in traumatic brain injured and normal subjects. Neuropsychologia 35: 747-758. 
Rosse RB, Schwartz BL, Zlotolow S, Banay-Schwartz M, Trinidad AC, Peace TD et al (1992). Effect of a low-tryptophan diet as an adjuvant to conventional neuroleptic therapy in schizophrenia. Clin Neuropharmacol 15: 129-141.

Rossi A, Arduini L, Daneluzzo E, Bustini M, Prosperini P, Stratta P (2000). Cognitive function in euthymic bipolar patients, stabilized schizophrenic patients, and healthy controls. $J$ Psychiatr Res 34: 333-339.

Rubinsztein JS, Michael A, Paykel ES, Sahakian BJ (2000). Cognitive impairment in remission in bipolar affective disorder. Psychol Med 30: 1025-1036.

Rubinsztein JS, Rogers RD, Riedel WJ, Mehta MA, Robbins TW, Sahakian BJ (2001). Acute dietary tryptophan depletion impairs maintenance of 'affective set' and delayed visual recognition in healthy volunteers. Psychopharmacology (Berl) 154: 319-326.

Savard RJ, Rey AC, Post RM (1980). Halstead-Reitan Category Test in bipolar and unipolar affective disorders. Relationship to age and phase of illness. J Nerv Ment Dis 168: 297-304.

Schmitt JA, Jorissen BL, Sobczak S, van Boxtel MP, Hogervorst E, Deutz NE et al (2000). Tryptophan depletion impairs memory consolidation but improves focussed attention in healthy young volunteers. J Psychopharmacol 14: 21-29.

Schmitt JAJ, Ramaehers JG, Kruizinga MJ, Van Boxtel MPJ, Vauerman EFPM, Reidel WJ (2002). Additional dopamine reuptake inhibition attenuates vigilance decrement induced by serotonergic reuptake inhibition in man. Journal of Psychopharmacology 16: 207-214.

Scott J, Stanton B, Garland A, Ferrier IN (2000). Cognitive vulnerability in patients with bipolar disorder. Psychol Med 30: 467-472.

Shallice T (1982). Specific impairments of planning. Phil. 298: 199-209.

Sheehan D, Lecrubier Y, Janavs J, Knapp E, Weiller E (1994). MINI International Neuropsychiatric Interview. University of South Florida.

Sobczak S, Honig A, Nicolson N, Riedel WJ (2002a). Effects of Acute Tryptophan Depletion on mood and cortisol release in first-degree relatives of bipolar disorder patients and matched healthy control volunteers. Neuropsychopharmacology 27: 834-842.
Sobczak S, Honig A, Riedel WJ (2000). Acute Tryptophan Depletion in bipolar disorders; literature review and directives for further research. Acta Neuropsychiatrica 12: 69-72.

Sobczak S, Honig A, Van Duinen MA, Maes M, Riedel WJ (2002b). Mood, prolactine and cortisol responses following intravenous Ltryptophan challenge; evidence for serotonergic vulnerability in first-degree relatives of bipolar patients. Int J Neuropsychopharmacol 5: 249-254.

Sobczak S, Riedel WJ, Booij L, Aan het Rot M, Deutz NEP, Honig A (2002c). Cognition following Acute Tryptophan Depletion: differences between first-degree relatives of bipolar disorder patients and matched healthy control volunteers. Psychol Med 32: $503-515$

Stoll AL, Renshaw PF, Yurgelun-Todd DA, Cohen BM (2000). Neuroimaging in bipolar disorder: what have we learned? Biol Psychiatry 48: 505-517.

Stroop JR (1935). Studies of interference in serial verbal reactions. J Exp Psychol 18: 643-662.

van Gorp WG, Altshuler L, Theberge DC, Mintz J (1999). Declarative and procedural memory in bipolar disorder. Biol Psychiatry 46: 525-531.

van Gorp WG, Altshuler L, Theberge DC, Wilkins J, Dixon W (1998). Cognitive impairment in euthymic bipolar patients with and without prior alcohol dependence. Arch Gen Psychiatry 55: 41-46.

Winokur A, Lindberg ND, Lucki I, Phillips J, Amsterdam JD (1986). Hormonal and behavioral effects associated with intravenous L-tryptophan administration. Psychopharmacol Berl 88: $213-219$.

Wolfe J, Granholm E, Butters N, Saunders E, Janowsky D (1987). Verbal memory deficits associated with major affective disorders: a comparison of unipolar and bipolar patients. J Affect Disorders 13: 83-92.

Young RC, Biggs JT, Ziegler VE, Meyer DA (1978). A rating scale for mania: reliability, validity and sensitivity. Br J Psychiatry 133: 429-435.

Young LT, Warsh JJ, Kish SJ, Shannak K (1994). Reduced brain 5$\mathrm{HT}$ and elevated NE turnover and metabolites in bipolar affective disorder. Biol Psychiatry 35: 121-127. 